\title{
A Randomized Controlled Study of Prophylactic Use of Umbilical Vein Oxytocin in The Management of Third Stage of Labor.
}

\author{
${ }^{1}$ Aranjana Manhas, ${ }^{2}$ Humma Habib, ${ }^{3}$ Syed Naseer, ${ }^{4}$ Nighat Firdous \\ ${ }^{1,2,3}$ Department of Gynecology and Obstetrics, SKIMS Medical College Srinagar, J\&K, India. \\ ${ }^{4}$ Department of Gynecology and Obstetrics, Lalla Ded Hospital GMC Srinagar. J\&K India.
}

\begin{abstract}
The present study has been undertaken to evaluate the efficacy of umbilical vein oxytocin in minimising the blood loss during third and fourth stage of labor in comparison with umbilical vein injection of saline only and with systemic methylergometrine. We performed a randomised control study involving three hundred women who were randomized into 3 groups of hundred women in each group.. Group 1 received umbilical vein injection of oxytocin. Group 2 received intraumbilical vein saline injection while subjects in group 3 were managed with systemic methylergometrine, $0.2 \mathrm{mg}$ intravenous at the delivery of anterior shoulder The primary outcome was measured in terms of duration of third stage of labor,blood loss, number of undelivered placenta and need for further oxytocics. Secondary outcomes were in terms of pre-delivery and post-delivery haemoglobin and haematocrit estimation.Intraumbilical oxytocin significantly shortens the duration of third stage of laborwhen compared with intraumbilical saline as well as systemic methylergometrine. It is also effective in reducing the amount of blood loss when compared to intraumbilical saline injection, but it was comparable in efficacy to methylergometrine in preventing amount of blood loss.
\end{abstract}

Key words:Intraumbilical oxytocin, postpartumhemorrhage, third stage of labor

\section{Introduction}

The third stage of labor begins immediately after delivery of the fetus and involves the separation and expulsion of the placenta and membranes. Pathological condition of third stage of labor constitutes a frequent and significant component of maternal complications in labor. Better understanding of third stage and its mechanisms may contribute to improved medical treatment and diminished maternal morbidity. (1) Complications can occur unexpectedly at this stage and unless prompt action is taken, serious maternal morbidity and sometimes mortality can occur. The most common complication is postpartum haemorrhage, which remains a leading cause of maternal mortality (25\%) especially in developing countries. ${ }^{(2)}$. A third stage of labor which exceeds 30 minutes is associates with a significant risk of postpartum haemorrhage and puerperal infection. A retained placenta is usually diagnosed when the duration of third stage of labor exceeds 30 minutes $^{(3,4)}$.

The best preventive strategy for above complications is active management of third stage of labor. ${ }^{(5)}$ Hospital guidelines encouraging this practice have resulted in significant reductions in the incidence of massive hemorrhage. ${ }^{(6)}$ Active management includes administration of oxytocin within one minute of birth of baby, clamping of the cord once it stops pulsating, controlled cord traction and massage of the fundus of the uterus until it is contracted. ${ }^{(7)}$ Active management of third stage of labor is evidence based, feasible and low cost intervention to prevent postpartum hemorrhage and can prevent $60 \%$ to $70 \%$ of atonic postpartum hemorrhage. ${ }^{(8)}$

The present study has been undertaken to evaluate the efficacy of umbilical vein oxytocin in minimizing the blood loss during third stage of labor in comparison with umbilical vein injection of saline only, andwith systemic methylergometrine.

\section{Materials And Methods}

O ur study was conducted in the postgraduate department of Obstetrics and Gynecology, Lalla Ded hospital, Government Medical College, Srinagar. Three hundred parturients were randomized into groups of hundred each. Inclusion criteria were age less than 35 years, parity less than 4 and singleton pregnancies with no cephalopelvic disproportion. Patients with known risk factors for postpartum hemorrhage like previous cesarean section, intrauterine fetal demise, hypertensive disorders, antepartum hemorrhage and polyhydramnios were excluded from study.

Group I received intraumbilical oxytocin ( 20 units in $20 \mathrm{ml}$ of normal saline) by direct injection into the umbilical vein immediately after cord clamping,Group II received intraumbilical normal saline $(20 \mathrm{ml})$ and Group III received systemic methylergometrine $(0.2 \mathrm{mg}$ i.v) at the delivery of the anterior shoulder. 
Delivery details were noted regarding mode of delivery, duration of third stage of labor, blood loss during delivery and time required for expulsion of placenta. Blood loss in immediate postpartum period was measured by collecting the blood in the tray below the perineum and later measuring the collected blood in a measuring flask. In patients who underwent episiotomy gauzepacking's were used which were kept in vagina after delivery of baby and placenta for one hour and weighed before and after use to estimate the blood loss. Number of patients with undelivered placenta after 15 minutes was noted in each group. Need for further oxytocics, blood transfusion or blood products were noted in each group. Also differences between pre delivery and 24 hours post-delivery hemoglobin and hematocrit were noted.

\section{Results}

In our study, mean age in group I was 26.72 years, 26.90 years in group II and 27.17 years in group III,there being no significant difference in mean age between three groups. We randomly included patients with parity less than 4.

The duration of third stage of labor ( 3 minutes 17 seconds) was significantly shorter in group I when compared with the other two groups ( 8 minutes 22 seconds and 4 minutes 6 seconds respectively).

TABLE 1: Duration of $3^{\text {rd }}$ stage of labor $(n=300)$

\begin{tabular}{|c|c|c|c|c|}
\hline \multirow{2}{*}{ Group } & \multicolumn{3}{|c|}{ Duration of $3^{\text {rd }}$ Stage of Labor } & p value \\
\hline & Min. & Max. & Mean & \multirow{4}{*}{$<0.001$} \\
\hline Group I & 45 secs & $7 \mathrm{~min}$ & $\begin{array}{c}3 \min 17 \operatorname{secs} \pm 1 \\
\operatorname{secs}\end{array}$ & \\
\hline Group II & $4 \min 45$ secs & $16 \min 46 \mathrm{secs}$ & $8 \min 22 \operatorname{secs} \pm 2 \min$ & \\
\hline Group III & $1 \mathrm{~min}$ & $15 \mathrm{~min} 12 \mathrm{secs}$ & $4 \min 6 \operatorname{secs} \pm 2 \min$ & \\
\hline
\end{tabular}

The average blood loss in $\mathrm{ml}$ during third and fourth stage of labor was 107.11 in group I, 195.04 in group II and 113.17 in group III thus making intraumbilical oxytocin comparable in efficacy with methylergometrine in preventing amount of blood loss.

TABLE 2: Comparison of blood loss (ml) during $3^{\text {rd }}$ and $4^{\text {th }}$ stage of labor $(n=300)$

\begin{tabular}{|l|l|l|l|}
\hline Group & Blood Loss & Statistical Analysis \\
\hline \multirow{2}{*}{ Group I } & \multirow{2}{*}{ Group II } & Normal Saline & $\mathrm{p}<0.001$ \\
\cline { 3 - 4 } & \multirow{2}{*}{$195.11 \pm 13.86$} & Methylergometrine & $\mathrm{p}>0.05$ \\
\hline \multirow{2}{*}{ Group III } & \multirow{2}{*}{\begin{tabular}{l} 
Oxytocin \\
\cline { 3 - 4 }
\end{tabular}} & Methylergometrine & $\mathrm{p}<0.001$ \\
\cline { 3 - 4 } & & Oxytocin & $\mathrm{p}>0.001$ \\
\cline { 3 - 4 } & & Normal Saline & $\mathrm{p}<0.001$ \\
\hline
\end{tabular}

The drop in hemoglobin (gm.\%) 24 hours after delivery was $0.68+$ in group I,1.58+0.41 in group II and $0.77+0.38$ in group III. The side effects like vomiting,abdominal pain and tachycardia was observed in fewer patients in group I as compared to the other two groups, the maximum being in group III i.e. patients receiving methylergometrine.

TABLE 3: Comparison of prepartum-postpartum hemoglobin difference (gm\%) among Intraumbilical oxytocin, Intraumbilical Saline and Intravenous Methylergometrine Groups ( $\mathrm{n}=300)$

\begin{tabular}{|c|c|c|c|c|l|}
\hline Group & $\begin{array}{c}\text { Pre-partum } \\
(\mathbf{H b})\end{array}$ & $\begin{array}{c}\text { Post-partum } \\
(\mathbf{H b})\end{array}$ & \multirow{2}{*}{ Difference } & \multicolumn{2}{|c|}{ Statistical Analysis } \\
\hline Group I & $9.96 \pm 0.85$ & $9.28 \pm 0.83$ & $0.68 \pm 0.37$ & Normal Saline & $\mathrm{P}<0.001$ \\
\cline { 5 - 6 } & & & Methyl-ergometrine & $\mathrm{P}>0.05$ \\
\hline Group II & $10.11 \pm 0.71$ & $8.53 \pm 0.50$ & $1.58 \pm 0.41$ & Oxytocin & $\mathrm{P}<0.001$ \\
\cline { 5 - 6 } Group III & $9.80 \pm 0.82$ & $9.03 \pm 0.76$ & $0.77 \pm 0.38$ & Methyl-ergometrine & $\mathrm{P}<0.001$ \\
\cline { 5 - 6 } & & & & Oxytocin & $\mathrm{P}>0.05$ \\
\hline
\end{tabular}

The percentage of undelivered placentas beyond 15 minutes was $0 \%$ in group I,3\% in group II and $1 \%$ in group III, the difference being statistically non-significant. 
Randomized Controlled Study of prophylactic use of Umbilical vein oxytocin in the management of

TABLE 4: Percentage of undelivered placenta after 15 minutes $(n=300)$

\begin{tabular}{|c|c|c|c|c|}
\hline Group & No. of Patients & Percentage (\%) & \multicolumn{2}{|c|}{ Statistical Analysis } \\
\hline \multirow{2}{*}{ Group I } & \multirow{2}{*}{0} & \multirow{2}{*}{0} & Normal Saline & $\mathrm{P}=0.24$ \\
\cline { 3 - 5 } & \multirow{2}{*}{ Group II } & \multirow{2}{*}{3} & Methergin & $\mathrm{P}=0.31$ \\
\hline \multirow{2}{*}{ Group III } & \multirow{2}{*}{1} & \multirow{2}{*}{1} & Oxytocin & $\mathrm{P}=0.24$ \\
\cline { 3 - 5 } & & & Oxythergin & $\mathrm{P}=0.61$ \\
\hline
\end{tabular}

Need for further oxytocics was significantly less in group I,when compared to other two groups(3,14 and 5 subjects respectively).

\section{Discussion}

The third stage of labor begins immediately after delivery of the fetus and involves separation and expulsion of the placenta and membranes. ${ }^{(3)}$ Pathological condition of the third stage of labor constitutes a frequent and significant component of maternal complications in labor, thus providing scope for devising better management protocols to decrease maternal morbidity. ${ }^{(1)}$

Adequate retraction of uterus in the third stage is essential for placental separation and thus in controlling postpartum hemorrhage. Postpartum hemorrhage occurs in women with risk factors like multiplepregnancy, fetal macrosmia,prolonged third stage and it also occurs in women with no known risk factors thus necessitating need for a physician's preparedness in dealing with it. ${ }^{(9)}$ Strategies for minimizing the effect of post-partum hemorrhage include identifying the risk factors and correcting them wherever possible and eliminating the routine episiotomy.Hospital guidelines encouraging the active management of third stage of labor have resulted in significant reductions in the incidence of massive hemorrhage. ${ }^{(10)}$

Delivery of high concentration of oxytocin directly to the placental site may result in more efficient myometrial contraction and placental separation occurs when the uterine wall beneath the placental site contracts.one possible method to facilitate this is to deliver oxytocin beneath the placental site through umbilical vein injection. ${ }^{(11)}$ oxytocin injected into the umbilical vein reaches the placental bed in relatively high concentration. This stimulates uterine contractions, thus decreasing the placental attachment site. The resulting tension causes decidua spongiosa to give way with the formation of a hematoma which then accelerated the process of placental separation and expulsion, thus resulting in a shorter duration and amount of blood loss during the third stage of labor. ${ }^{(12)}$

\section{Conclusion}

Umbilical vein oxytocin is effective in shortening the third stage of labor for prevention of immediate postpartum hemorrhage. This method could be of use in women in whom intravenous access is limited or it is desirable to limit the intravenous fluids and in whom it is desirable to hold blood loss to a minimum. ${ }^{(13)}$ It has also got an advantage over, methylergometrine whose side effects restrict its use in hypertensive patients, heart disease and severe anemia. This review concludes that, in settings with limited facilities, oxytocin injected into the umbilical vein could improve some of the maternal outcomes. . More patients would be needed to definitively study the effects of the procedure on hematological parameters. Hence, the results of the review are applicable in under-resourced settings where complications of third stage of labor are common and facilities for immediate surgical intervention are limited.

\section{References}

[1] Arie Herman,MD,Zwi weinraub,MD,Ian BukovskyMD,Shlomo Arieli,MD,Philip Zabow,MD, Eliahu Caspi,MD,and Raphael RonEL,MD. Dynamic ultrasonographic imaging of the third stage of labor; new perspectives into third stage mechanisms. Am J Obstet Gynecol 1993; 168:1496-9.

[2] Chamberlain GVP. The clinical aspects of massive haemorrhage. In: Patel N (ed.).Maternal mortality-the way forward. London: Royal College of Obstetricians and Gynaecologists 1992; 54-62.

[3] Cunningham FG,MacDonald PC,Gant NF,Leveno KJ,Gilstrap LC. Williams Obstet $19^{\text {th }}$ ed.East Norwalk Appleton\& Lange, 1993;615-25.

[4] Dombrowski MP,Bottoms SF,Saleh AA, Hurd WW,Romero R. Third stage of labor:analysis of duration and clinical practice. Am J Obstet Gynecol 1995; 172:1279-84.

[5] Prendiville WJ, Elbourne DR and Mc Donald S (1996) Active versus expectant management of the third stage oflabour. The Cochrane library, issue 1. Oxford: Update software, 1997.

[6] Anderson JM,Etches D. prevention and management of postpartum haemorrhage. Am Fam Physician 2007; 75:875-82.

[7] M Patil. Active management of third stage of labor. Principles and practice of Obstetrics and Gynaecology for PG. A FOGSI Publication, Vol.1.2008; P351.

[8] PK Sekharan. Prevention and prediction of postpartum haemorrhage. FOGSI FOCUS January 2007.

[9] Sherman SJ,Greenspoon JS,Nelson JM,Paul RH. Identifying the obstetric patient at high risk of multiple unit blood transfusions. J Reprod Med. 1992; 37:649-52.

[10] Anderson JM,Etches Prevention and management of post-partum haemorrhage. Am Fam Physician 2007; 75:875-82. 
[11] M.R Gaznavi, MD et al. intraumbilical oxytocin for the management of retained placenta: A randomized controlled trial. Obstet Gynecol 1998; 91:203-7.

[12] Shrestha P, Babu CS.Influence of umbilical vein oxytocin on blood loss and length of third stage of labour.Nepal Med Coll J. 2007 Sep;9(3):176-8.

[13] Chestnut DH, Wilcox LL. Influence of umbilical vein administration of oxytocin in the third stage of labour: a randomized doubleblind placebo-controlled study. Am J Obstet \& Gynecol 1987; 157:160-162.

\section{AUTHORS}

First Author- Aranjana Manhas, M.D. Senior Resident ,Department of Gynecology and Obstetrics, SKIMS Medical College Srinagar, J\&K, India.

Second Author- Humma Habib, M.D. Senior Resident ,Department of Gynecology and Obstetrics, SKIMS Medical College Srinagar, J\&K, India.

Third Author- Syed Naseer, M.D. Lecturer, Department of Gynecology and Obstetrics, SKIMS Medical College Srinagar, J\&K, India.

Fourth Author-Nighat Firdous, M.D. Associate Professor, Department of Gynecology and Obstetrics, Lalla Ded Hospital GMC Srinagar. J\&K India.

Correspondence Author-Humma Habib, M.D. Senior Resident, Department of Gynecology and Obstetrics, SKIMS Medical College Srinagar, J\&K, India. 